\title{
O enfermeiro e a criança: a prática do brincar e do brinquedo terapêutico durante a hospitalização
}

\section{The nurse and the child: therapeutic toy and the practice of playing during hospitalization}

\author{
Charlene da Silva ${ }^{1}$, Flávia Medeiros Schmidt ${ }^{2}$, \\ Antônia Maria Grigol ${ }^{3}$, Lidiane Ferreira Schultz ${ }^{4}$
}

Resumo

\begin{abstract}
Objetivou-se identificar o conhecimento dos enfermeiros quanto à prática do brincar e do Brinquedo Terapêutico na hospitalização da criança. Estudo descritivo com abordagem qualitativa, realizado com 10 enfermeiros que atuam em um hospital público infantil no Norte de Santa Catarina, por meio de uma entrevista semiestruturada, no ano de 2018. Os dados foram analisados conforme o método da análise temática. Emergiram quatro categorias temáticas: o brincar e o enfermeiro; o brincar como parte do tratamento; o brincar em um ambiente favorável; a abordagem do enfermeiro e o uso do brinquedo/Brinquedo Terapêutico. Os resultados mostram que os enfermeiros reconhecem a importância do brincar durante a hospitalização da criança, considerado uma forma de aproximação com o infante. Verifica-se também o desconhecimento dos enfermeiros em relação à tecnologia do uso do Brinquedo Terapêutico durante a hospitalização como uma ferramenta de cuidados da enfermagem. Ressalta-se a importância da abordagem deste conteúdo nos cursos de graduação em enfermagem, especialização e residência em enfermagem pediátrica e a realização de cursos de capacitação para os profissionais da prática assistencial.
\end{abstract}

Palavras-chave: Enfermagem pediátrica. Jogos e brinquedos. Criança hospitalizada. Cuidados de enfermagem.

1 Especialização em Enfermagem em Pediatria e Cuidados Intensivos Neonatais pela Faculdade Pequeno Príncipe, Curitiba, Paraná, Brasil. Graduação em Enfermagem pela Faculdade IELUSC, Joinville, Santa Catarina, Brasil.

2 Graduação em Enfermagem pela Faculdade IELUSC, Joinville, Santa Catarina, Brasil.

3 Mestrado em Saúde e Meio Ambiente pela Universidade da Região de Joinville, Joinville, Santa Catarina, Brasil. Docente Titular do Curso de Graduação em Enfermagem da Faculdade IELUSC, Joinville, Santa Catarina, Brasil.

4 Doutoranda em Saúde e Meio Ambiente pela Universidade da Região de Joinville, Joinville, Santa Catarina, Brasil. Docente Adjunta do Curso de Graduação em Enfermagem da Faculdade IELUSC, Joinville, Santa Catarina, Brasil. E-mail: lidiane.schultz@amsic.com.br 


\begin{abstract}
The objective of this study was to identify nurses' knowledge regarding the practice of playing and Therapeutic Toy in the hospitalization of children. Descriptive study with qualitative approach, conducted with ten nurses who work in a public children's hospital in northern Santa Catarina through a semi-structured interview, in 2018. The data were analyzed according to the thematic analysis method. Four thematic categories emerged: play and the nurse; play as part of treatment; play in a favorable environment; the nurse's approach and the use of the toy/Therapeutic Toy. The results show that nurses recognize the importance of playing during the child's hospitalization, considered a way of approaching the infant. Nurses' lack of knowledge regarding the technology of the use of the Therapeutic Toy during hospitalization as a nursing care tool is also verified. We emphasize the importance of addressing this content in undergraduate nursing, specialization and residency courses in pediatric nursing and conducting training courses for healthcare professionals.
\end{abstract}

Keywords: Pediatric nursing. Play and playthings. Hospitalized children. Nursing care.

\section{Introdução}

O brincar, estudar e realizar atividades diárias em seu ambiente de familiaridade fazem parte do processo de crescimento e desenvolvimento esperado na infância. Winnicott, em 1975, afirmava que a brincadeira é universal, que facilita o crescimento e, portanto, a saúde. ${ }^{(1)} \mathrm{O}$ brincar constitui um dos aspectos mais importantes na vida da criança e deve ser priorizado. ${ }^{(2-4)}$

$\mathrm{Na}$ infância, essa atividade estimula o desenvolvimento motor, emocional, cognitivo, sensoriais, de linguagem, mental e social da criança. Possibilita a inserção na cultura em que vive, a inter-relação com o meio ambiente, a construção de representações mentais, a organização de ideias e pensamentos, estimula a criatividade e desenvolve habilidades, favorece a expressão de sentimentos, prepara a criança para o futuro imediato e tardio, além de melhorar a estrutura e função do cérebro. ${ }^{(5)}$

A avaliação do brincar na criança também possibilita indicar os estágios do desenvolvimento infantil e possíveis atrasos. ${ }^{(6)}$ As brincadeiras podem ser classificadas em quatro tipos: recreativa, estimuladora, socializadora e terapêutica ou catártica.

No hospital, essa atividade funciona como uma ferramenta facilitadora na compreensão do diagnóstico clínico para a criança e sua família, na realização dos procedimentos de enfermagem e na adaptação da criança no ambiente hospitalar. ${ }^{(7)}$
A brincadeira Terapêutica possibilita à criança expressar seus sentimentos e vivências em situações novas e/ou difíceis, atuando como "válvula de escape", diminuindo a ansiedade, tensão, medo e esclarecendo as dúvidas durante a hospitalização. ${ }^{(1-3,7)}$

Em consonância, um estudo realizado em Hong Kong apresentou que a internação, juntamente com todo o processo de adoecimento e mudanças da rotina diária, pode influenciar a saúde emocional da criança, potencializando o nível de estresse ao longo da hospitalização e desenvolvendo reações de ansiedade, medo, culpa e preocupações relacionadas à separação ou ausência de alguns membros da família. ${ }^{\left({ }^{8}\right)}$

Pesquisas apontam que durante a hospitalização os procedimentos invasivos e dolorosos são momentos extremamente difíceis para as crianças; todavia, uma forma de amenizar esse sofrimento é incorporar no processo de sistematização da assistência em enfermagem e no cotidiano hospitalar o brincar, a brincadeira e o uso do brinquedo terapêutico durante a hospitalização infantil. ${ }^{(9-11)}$ Entretanto, o enfermeiro precisa estar qualificado e conhecer ferramentas que possam ser utilizadas para garantir a assistência atraumática, respeitando os direitos da criança hospitalizada e de sua família. ${ }^{(12)}$

Tal direito da criança é garantido pela Resolução $n^{0} 41$ do Conselho Nacional dos Direitos da Criança e do Adolescente Hospitalizado 
(CONANDA), de 13 de outubro de 1995, a qual dispõe: "a desfrutar de alguma forma de recreação, programas de educação para a saúde, durante sua permanência hospitalar". ${ }^{(13)}$ Entre as ferramentas de cuidado, destaca-se a utilização da técnica do brinquedo/Brinquedo Terapêutico (BT) como uma tecnologia na assistência à criança hospitalizada, que é garantida à equipe de Enfermagem pelo Conselho Federal de Enfermagem em sua Resolução $n^{\circ}$ 295/2004, revogada pela Resolução 546/2017. ${ }^{(9)}$ No Artigo $2^{\circ}$, a utilização da técnica do BT deverá contemplar as etapas do Processo de Enfermagem com seu devido registro em prontuário, enquanto documento legal, de forma clara, legível, concisa, datado e assinado pelo profissional. ${ }^{(14)}$

O BT é uma técnica estruturada, utilizada, inicialmente, por Erickson a partir de $1958,{ }^{(15)}$ que pode ser aplicada em diferentes unidades de atendimento à criança, como unidades de internação, centro cirúrgico, ambulatórios, unidades de terapia intensiva e salas de espera de emergências. ${ }^{(16-18)}$ É classificado em três tipos: dramático, que objetiva a descarga emocional e catarse da criança; o instrucional, que prepara a criança para os procedimentos; e o capacitador de funções fisiológicas, que visa potencializar o uso das funções fisiológicas da criança de acordo com a sua condição. ${ }^{(15)}$

A escolha pelo enfermeiro do BT dramático, instrucional ou o capacitador de funções fisiológicas depende da idade, do crescimento e desenvolvimento, e das necessidades específicas no processo de adoecimento e hospitalização da criança. Para cada tipo de BT algumas etapas específicas precisam ser realizadas, ${ }^{(15)}$ e a criança precisa sempre ser convidada a brincar, ter livre escolha para a participação da família e do local que deseja realizar a sessão de BT. (9,19-21) $^{-1}$

Pesquisas nacionais e internacionais evidenciam os múltiplos benefícios do BT para a criança, família, equipe de enfermagem e instituições hospitalares. ${ }^{(9,19-21)}$ A utilização do BT faz com que a criança adquira maior compreensão dos procedimentos a serem executados, permite exteriorização de sentimentos, catarse por meio do alívio de ansiedades e receios, autoconfiança e preparo para o autocuidado, domínio dos procedimentos a serem realizados, fortalecimento das suas potencialidades e competências, diminuição das queixas de dor, melhora da frequência cardíaca e pressão arterial, diminuição da necessidade de sedação, redução do estresse e do choro, além de promover segurança e a socialização da criança e de sua família. ${ }^{(9,19-21)}$ A aplicação da técnica do BT durante a hospitalização da criança também permite estabelecer uma comunicação efetiva, vínculo e aproximação entre o enfermeiro e o infante. . $^{(72)}$

Entretanto, o uso dessa tecnologia de cuidado ainda é restrito nos ambientes de saúde, tendo os enfermeiros relatados dificuldades para incorporação ao processo de trabalho, falta de conhecimento da temática, insegurança para utilização do BT ou desvalorização do brincar e do uso do BT com a criança e sua família. (22-24)

Nesta perspectiva, a importância desse profissional em tornar-se um enfermeiro brincante, permitindo o brincar lúdico e recreacional da criança e incorporando o BT de maneira sistematizada inerente ao modelo de cuidado e assistência na pediatria. Assim, investigar sobre o conhecimento dos enfermeiros que trabalham na pediatria sobre a temática faz-se relevante. Outra justificativa da realização desta pesquisa refere-se a limitados estudos nacionais e internacionais sobre o conhecimento do enfermeiro para desenvolver e aplicar a técnica do brinquedo terapêutico. Este estudo teve como objetivo identificar o conhecimento dos enfermeiros quanto à prática do brincar e o uso do BT na hospitalização da criança em um hospital pediátrico.

\section{Material e Método}

Pesquisa descritiva com abordagem qualitativa realizada em um hospital infantil localizado no Norte do estado de Santa Catarina.

Nesta pesquisa, o conceito de brincar referese a uma ação realizada, objetivando o vínculo entre a criança e a equipe de enfermagem, sendo a brincadeira um processo de distração e diversão e 
o BT uma tecnologia de cuidado de enfermagem.

Os critérios de inclusão para a participação deste estudo foram: enfermeiros que pertencem ao quadro efetivo do hospital há mais de três meses, de diferentes turnos e unidades de cuidado. Foram estabelecidos como critérios de exclusão: enfermeiros que estavam em período de treinamento e que se encontravam em afastamento por motivo de atestado médico ou em período de férias no momento da realização da coleta de dados.

Anteriormente ao início da coleta dos dados, os pesquisadores estiveram com as coordenadoras de enfermagem do hospital nos três turnos de trabalho e, juntamente, foram às unidades para apresentação do projeto de pesquisa e realizaram o convite aos enfermeiros. Os mesmos foram informados sobre a finalidade da pesquisa, objetivos, métodos, riscos e benefícios com garantia de sigilo e anonimato.

Quando aceitaram participar voluntariamente da pesquisa, foi agendada a melhor data, com horário e local de preferência dos participantes para a realização da coleta dos dados, e o Termo de Consentimento Livre e Esclarecido foi assinado pelo participante e pesquisadoras. Todos os enfermeiros optaram em realizar a entrevista no próprio local de trabalho, sendo, então, disponibilizada pela coordenação de enfermagem uma sala de reunião, local reservado e calmo que favoreceu a garantia da privacidade do pesquisador e participante. Em nenhum momento da coleta dos dados a entrevista foi interrompida por outras pessoas. O enfermeiro participante do estudo foi substituído na sua unidade de trabalho durante a entrevista por outro enfermeiro, conforme organização da coordenadora de enfermagem.

Participaram deste estudo 10 enfermeiros, dentre eles, quatro eram do sexo masculino e seis do sexo feminino, com idade entre 25 e 44 anos. $\mathrm{O}$ tempo de trabalho na área da pediatria variou entre seis meses a 11 anos; o tempo de formação variou entre cinco meses a 14 anos. Dentre os enfermeiros, cinco informaram que possuem filhos. No que se refere aos setores de atuação no momento da entrevista, três enfermeiros atuam no setor de internação clínica, dois no setor de cardiologia, dois na internação psiquiátrica, um no setor ortopédico, um no pronto-socorro e um enfermeiro que trabalha em diferentes unidades de internação.

Acoleta de dados foi realizada no ano de 2018, pelos próprios pesquisadores treinados. No intuito de garantir a qualidade dos dados, foi realizado um pré-teste e não houve a necessidade de modificar o instrumento; no entanto, esse enfermeiro não foi incluído no estudo. Foi realizada uma entrevista semiestruturada, tendo como pergunta norteadora para o estudo: "Como você pratica o brincar com a criança no ambiente hospitalar?”. Essa questão norteadora foi construída em conjunto com outra pesquisadora membro de um grupo de pesquisa sobre a temática do BT. Outras perguntas também foram feitas, conforme o desenvolver da entrevista. Perguntas que contemplavam sobre os dados socioeconômicos foram realizadas, a fim de caracterizar os participantes.

As entrevistas tiveram uma duração entre 25 a 40 minutos. Para o registro, documentação e transcrição na íntegra das entrevistas foi utilizado o recurso de gravação de voz, para posterior análise dos dados. A coleta de dados foi finalizada quando se obteve a saturação dos dados..$^{(25)}$

Para a interpretação dos dados da pesquisa foi utilizada a análise temática proposta por Minayo. ${ }^{(26)}$ Essa proposta tem como foco principal descobrir os núcleos dos sentidos que compõem uma comunicação, cuja presença ou frequência signifiquem alguma coisa para o objeto analítico, a partir das fases de pré-análise, exploração do material e tratamento-interpretação. ${ }^{(26)}$

Emergiram quatro categorias temáticas: 1) $\mathrm{O}$ brincar e o enfermeiro; 2) $\mathrm{O}$ brincar como parte do tratamento; 3) $\mathrm{O}$ brincar em um ambiente favorável; 4) A abordagem do enfermeiro e o uso do brinquedo/Brinquedo Terapêutico. Os participantes da pesquisa foram identificados com a letra $\mathrm{E}$ (enfermeiro) e um número, conforme a ordem de realização da entrevista durante a coleta dos dados, garantindo, assim, o anonimato dos participantes.

A pesquisa foi realizada após a aprovação pelo Comitê de Ética em Pesquisa da Associação 
Educacional Luterano Bom Jesus - IELUSC com parecer número 05.1144/2018 e autorizado pela instituição hospitalar por meio do Termo de Exequibilidade em concordância com os preceitos éticos exigidos pela Resolução 466/2012. ${ }^{(27)}$

\section{Resultados}

\section{O brincar e o enfermeiro}

Os participantes, ao serem questionados sobre o significado do brincar de um modo geral, responderam em sua totalidade sobre o brincar propriamente dito e o recreacional relacionado à internação. E identificou-se a partir das falas a essência do seu significado como sendo uma forma de interação, distração, alegria, diversão, ocupar o tempo, vínculo de confiança e lazer:

Ah, é o ato de mexer em algum objeto que dê alegria para o paciente, pra criança, ele está brincando até com uma caneta, ele pode brincar, brincar é alguma coisa que divirta o paciente. (E5)

Brincar, eu acredito assim: é uma forma da criança interagir, aproxima, e a gente acaba fazendo um vínculo de confiança com eles também; quando a gente está brincando é um momento de distrair, tirar um fator estressor dela de internação. (E1)

O brincar, além de ajudar a criança, ainda promove uma interação entre o paciente e a equipe de enfermagem [...]. (E10)

Para que esse brincar aconteça, alguns materiais são oferecidos pelos enfermeiros participantes deste estudo, de acordo com a disponibilidade na unidade de internação e brinquedoteca. Verifica-se também que o brincar possibilita aproximação e a interação enfermeirocriança, conforme relatos:

[...] eu utilizo os brinquedos que temos no setor, na sala de brinquedoteca e através de gestos, mímicas, conversa [...]. (E4)
[...] a gente brinca quando vai passar a visita, quando vai fazer o exame físico, com o estetoscópio, com o crachá [...]. (E2)

[...] a gente, na verdade, oferece folhas com desenhos, lápis de cor, giz de cera, e... se eles quiserem brincar no balcão, a gente acaba deixando, coloca uma cadeira e deixa brincar ali também, interagir com a equipe, porque não tem como não deixar interagir, ficam passando o tempo todo pela gente e conversando; então, acaba que vão parar no balcão também [...]. (E7)

Alguns limitadores para a prática do brincar com a criança no hospital foram descritos pelos participantes, como: a falta de tempo, preocupação com as atividades de rotina, a quantidade de funcionários e múltiplas atribuições. Em contrapartida, há um reconhecimento da importância de que essa atividade não seja interrompida durante a internação na pediatria.

Sim, influencia nas questões de rotinas mesmo. (E8).

[...] infelizmente, a gente não tem tanto tempo disponivel pra isso, devido nossa função, mas a gente sempre procura brincar de uma maneira melhor com a criança [...]. (E9)

A presença e participação dos voluntários e a equipe da terapia ocupacional como protagonistas dessa ação, em função da rotina diária da equipe de enfermagem e a quantidade de funcionários, foi descrita neste estudo:

[...] a enfermagem não consegue parar pra poder brincar, isso acaba sendo remanejado pra outros setores, pra TO, pra psicopedagoga, que ela que faz mais esse serviço, e para os voluntários. (E8)

Contudo, existe o incentivo por parte da instituição hospitalar em relação a promover o brincar, visto que a equipe multidisciplinar e os voluntários estão constantemente envolvidos nessa ação. A responsabilidade de brincar com a criança hospitalizada também foi referida como 
uma atividade de todos que estão em contato e no cuidado com a criança, seja a família, enfermagem, equipe médica, ou fisioterapeutas:

Acho que quem tem mais tempo seria o responsável que está com a criança [...] não tem como a equipe passar o maior tempo brincando com essa criança [...] (E4)

Acho que toda a equipe deve brincar com a criança, porque criança é criança! Então, tudo o que você vai fazer, você tem que tentar de uma forma lúdica; então, toda a equipe multidisciplinar tem que brincar. (E6)

\section{O brincar como parte do tratamento}

Nessa categoria, identificou-se que todos os participantes reconhecem a importância do brincar durante a hospitalização e permitem que a rotina diária da criança seja preservada, relatando que o brincar ajuda a tirar o foco da internação e auxilia na recuperação e no processo de melhora do tratamento. Foi apresentado também o reconhecimento por parte do enfermeiro, que o tratamento da doença envolve diversos contextos e ultrapassa o cuidado físico para o processo de recuperação da saúde:

Ah, sim, porque ela tem que manter a rotina dela dentro do hospital, não é porque ela está internada... por mais que nós tenhamos uma rotina e normas, ela (criança) tem que manter o que já trouxe de casa, o que ela já vem fazendo da rotina, então o brincar faz parte do tratamento também. (E4)

Acho que a brincadeira ajuda no processo de melhora do paciente, né; acho que a felicidade, essas coisas todas, o bem-estar da criança... tudo isso auxilia, né, no processo de melhora no tratamento. (E5)

\section{O brincar em um ambiente favorável}

Os enfermeiros, ao serem indagados sobre como proporcionam um ambiente favorável para que o brincar aconteça no hospital, citaram o uso da brinquedoteca, e dois participantes disseram que direcionam essa atividade para a equipe multidisciplinar:

Aqui nós temos um ambiente favorável, né, que são as brinquedotecas, como já falei pra vocês... mas, assim, você levando, às vezes, um brinquedo pra essa criança, você tentando animá-la de alguma maneira, um brinquedinho... você contribui com a criança. (E9)

Como as entrevistas foram realizadas com enfermeiros que atuam em uma instituição destinada ao atendimento exclusivamente infantojuvenil, ficou evidente a valorização de um ambiente favorável por parte do hospital e da equipe. Verificamos também a importância do enfermeiro atuante na pediatria em desenvolver uma visão holística e humanizada da assistência, identificando a necessidade da criança em brincar fora do quarto quando possível, uma vez que descreve o leito como sendo um local onde ocorrem procedimentos dolorosos e desagradáveis ao infante. O enfermeiro deve proporcionar um ambiente favorável para o brincar, solicitando brinquedos para a instituição e brincando verbalmente. A necessidade de maior envolvimento de toda a equipe multidisciplinar também foi descrita pelos participantes do estudo como importante para um ambiente favorável ao brincar no hospital.

Espaço físico fora do quarto, primeira coisa, porque o quarto está muito relacionado com procedimento e dor. (E3)

Olha, a enfermagem... pode envolver também a equipe multidisciplinar, né, porque é bem importante, né; no caso, nós temos a pedagoga aqui dentro, a terapeuta ocupacional, é interagir também com brinquedos, além do brincar verbal, toque, ainda seria interessante o uso do brinquedo. (E10)

Talvez solicitando pra instituição mais brinquedos, a pedagoga mais presente, talvez a TO também ali pra poder contribuir. (E7) 
A abordagem do enfermeiro e o uso do brinquedo/Brinquedo Terapêutico

Nessa categoria, nove participantes do estudo expuseram utilizar da brincadeira em suas abordagens, objetivando explicar à criança sobre procedimentos que seriam realizados, mesmo desconhecendo a tecnologia do uso do BT. O brincar é utilizado por esses profissionais objetivando tornar lúdico os procedimentos de enfermagem a serem realizados na criança hospitalizada.

Primeiro você chega brincando, pergunta... interage com a criança através da brincadeira, depois você começa a tocar nela; por exemplo, vou fazer uma ausculta: ah, a tia vai ver teu coração aqui, como que está batendo; aí, depois você começa; dessa forma ela vai ficando mais calma e você consegue trabalhar com ela. (E10)

Na abordagem mais interativa possivel (risos), são crianças; então, assim, nós adultos já não gostamos de levar uma agulhada, imagina elas, então a gente tenta falar: uma picadinha de formiga... de abelha, enfim, a gente tenta fantasiar o máximo possivel. (E9)

Um dos participantes descreve que explica de maneira clara e objetiva sobre os procedimentos que precisam ser realizados, criando, assim, um vínculo de confiança entre profissional e criança. Além da abordagem verbal, o enfermeiro possui outras ferramentas que facilitam e permitem avaliar diversos contextos de comportamento da criança durante a hospitalização. Quando questionados sobre a utilização da técnica do brinquedo/Brinquedo Terapêutico, os enfermeiros informaram não conhecer essa técnica, sendo que apenas uma enfermeira relatou imaginar que fosse algo que tinha visto em uma de suas experiências no ambiente hospitalar:

Eu abordo pelo nome, explico o que vai acontecer; se for doer eu aviso que vai doer, não minto de forma alguma de que não vai doer, porque vai doer e aí a criança passa não acreditar mais na gente; dessa forma, explico tudo que vai acontecer... é para o tratamento dela, da criança, pra melhorar a dor, né... o dodói (riso), mas dessa forma nunca menti. (E5)

Não sei o que é essa técnica do brinquedo terapêutico. (E6)

Técnica do brinquedo terapêutico? Desconheço. (E8)

[...] o brinquedo terapêutico seria a interação com brinquedos também, a gente tem uma experiência aqui na oncologia, onde trouxeram pra cá um brinquedo do Maurício (de) Souza, os bonequinhos, o Cebolinha e a Mônica; então, toda vez que você iria... por exemplo, eu vou fazer um procedimento nas crianças, eu primeiro faria no boneco pra depois fazer nas crianças; ah, eu vou fazer um curativo em um Cateter Central de Inserção Periférica, primeiro vamos fazer o curativo na Mônica, $e$ depois no paciente [...]. (E10)

Todavia, a técnica do brinquedo/Brinquedo Terapêutico vai muito além de seu relato, sendo um brinquedo estruturado que auxilia no preparo da criança para procedimentos, permitindo ainda que a criança alivie seus traumas e ansiedades.

[...] deixa eles mais calmos, eles interagem melhor com a gente [...] mas é muito interessante assim, a criança acalma, e você consegue fazer um trabalho bem melhor com eles [...]. (E10)

\section{Discussão}

O brincar, além de ser uma necessidade da infância, contribui para o desenvolvimento da saúde física, emocional e intelectual. Essa atividade lúdica proporciona a melhora do aprendizado, socialização e autoestima da criança. ${ }^{(7)}$

Nesta pesquisa, o brincar foi descrito pelos participantes como o recreacional que está relacionado à distração e diversão durante a hospitalização da criança, além de ser uma forma de aproximação e criação de vínculo com a equipe. O brincar também foi citado como um instrumento utilizado pelos enfermeiros para tornar lúdico os procedimentos de enfermagem realizados na criança, juntamente com o brincar verbal que 
aparece nesta pesquisa como uma forma de explicar os procedimentos invasivos antes de realizá-los.

A brincadeira faz parte da rotina da criança; dessa forma, não deve ser interrompida durante o processo de adoecimento e hospitalização, pois é durante o brincar que a criança desenvolve o seu imaginário, podendo recriar a realidade independente das condições clínicas de saúde e das capacidades físicas e neurológicas da criança. ${ }^{(28)}$

Pesquisas apontam que ocupar a criança com brinquedos e brincadeiras favorece a adaptação hospitalar, sendo uma alternativa na assistência de enfermagem que pode minimizar os efeitos da hospitalização, como ansiedade, medo e estresse. ${ }^{(7)}$

Os enfermeiros desta pesquisa relataram que o brincar ajuda a tirar o foco da internação, auxilia na recuperação e no processo de melhora do tratamento e permite que a rotina diária do brincar da criança seja preservada. Para que esse brincar no hospital aconteça, faz-se necessário um ambiente facilitador ou favorável; o uso da brinquedoteca foi citado pela maioria dos enfermeiros desta pesquisa.

De acordo com a Lei 11.104 de 21 de março de 2005, é obrigatória a instalação de brinquedotecas nas dependências dos hospitais que possuam atendimento pediátrico, sendo elas espaços designados ao estímulo da brincadeira entre crianças, acompanhantes e profissionais da saúde. ${ }^{(29)}$ Esse tipo de espaço deve ser um ambiente colorido, provido de brinquedos e jogos educativos ${ }^{(30)}$ objetivando também amenizar o sofrimento, desvinculando o leito hospitalar de um local que remete à dor e a procedimentos, para um ambiente que promove a socialização entre a família e as outras crianças, com momentos de lazer e distração. ${ }^{(31)}$

Atividades lúdicas durante a hospitalização da criança permitem que o enfermeiro otimize um ambiente mais acolhedor, ampliando a comunicação entre o profissional, criança e família. Estudo realizado em um hospital pediátrico do Nordeste brasileiro enfatizou que a abordagem mais eficaz na pediatria é por meio do brincar, quando é possível estabelecer uma comunicação com a criança em seu universo brincante e fantasioso, além de fortalecer as ações da enfermagem para o desenvolvimento do infante e para o cuidado à saúde. ${ }^{(11)}$ Assim, o enfermeiro precisa facilitar a inclusão dessas atividades no contexto assistencial associada a conhecimentos técnico-científicos e às necessidades emocionais e sociais da criança e de sua família. ${ }^{(7)}$

Os resultados permitiram descrever a importância e a valorização do brincar pelos participantes do estudo, objetivando interação, distração, alegria, lazer, aproximação e vínculo com a criança. A importância de se manter um diálogo verdadeiro com a criança, possibilitando que ela confie na equipe e participe do seu tratamento, foi também apresentada na fala dos enfermeiros. Compreender o seu tratamento, os procedimentos realizados, suas interfaces precisam estar presentes neste processo de saúdedoença da criança.

Dentre os limitadores para a prática do brincar com a criança no hospital, os participantes relataram a falta de tempo, preocupação com as atividades de rotina e a quantidade de funcionários devido suas atribuições. Esses resultados são ressaltados em outros estudos, os quais apontam dificuldades do enfermeiro para promover o brincar com a criança hospitalizada, a falta de tempo, falta de capacitação, preocupação com as atividades de rotina, excesso de trabalho administrativo e número insuficiente de funcionários..$^{(9,12,23)}$

A maioria dos participantes deste estudo não apresentaram a família como um facilitador para a prática do brincar no ambiente hospitalar. Contudo, a participação dos pais/família nas atividades lúdicas é um fator importante, pois transmite segurança e apoio à criança durante a internação, uma vez que são esses os conhecedores das preferências e hábitos do infante. ${ }^{(30)}$ Estudo aponta também que os responsáveis pela criança precisam ser envolvidos no processo de preparo da criança para procedimentos de enfermagem através do brincar, para compreender melhor o que será realizado, possibilitando o encorajamento e enfrentamento por ambos. ${ }^{(23)}$

Para o cuidado à criança, o enfermeiro 
precisa desenvolver suas capacidades lúdicas para tornar-se um enfermeiro brincante. Nesse sentido, é imprescindível que esse profissional realize abordagem adequada à criança, utilizandose de ferramentas estruturadas como o brinquedo/ Brinquedo Terapêutico.

O brincar com função terapêutica é descrito nesta pesquisa pelos participantes como atribuição de outros profissionais. Quando abordados sobre o uso do brinquedo/Brinquedo Terapêutico, os participantes desconheciam a técnica, sua aplicabilidade e importância para o enfermeiro, criança, família e instituição hospitalar, porém todos se mostraram interessados em conhecer sobre a temática e a serem capacitados para utilizar essa tecnologia como instrumento de intervenção assistencial.

Uma revisão integrativa descreveu que para os enfermeiros o BT constitui uma técnica estruturada que, além do preparo para os procedimentos quando utilizado como BT instrucional, possibilita a aproximação e vinculação, abrindo espaço para a compreensão das vivências e experiências da criança e sua família proporcionando uma assistência ampliada, efetiva e qualificada. ${ }^{(23)}$

Outra pesquisa aponta para o brincar e a técnica do BT como aliados dos enfermeiros na assistência, podendo promover o bem-estar psicofisiológico da criança. ${ }^{(30)} \mathrm{O} \mathrm{BT}$, enquanto uma tecnologia de cuidado, deve estar presente na sistematização da assistência de enfermagem, a fim de gerenciar e planejar o cuidado; dessa forma, fazse possível organizar as atividades de enfermagem sem deixar de promover o cuidado lúdico.

\section{Conclusão}

O estudo possibilitou reconhecer a importância do brincar como forma de vínculo da criança com os enfermeiros durante a hospitalização, bem como seus benefícios enquanto uma atividade recreativa para a diversão, distração e para tornar lúdico os procedimentos de enfermagem realizados na pediatria.
Também foi possível apontar que os enfermeiros compreendem a necessidade de ser um enfermeiro que brinca ou um profissional que possibilite um ambiente favorável para o brincar, estando esses conscientes de que o brincar e as brincadeiras fazem parte da rotina da criança e que durante a hospitalização auxiliam no tratamento e recuperação.

Obrinquedoterapêutico comoumatecnologia estruturada para o cuidado que deve constar no planejamento da assistência e na avaliação da criança hospitalizada não é reconhecido e aplicado na prática pelos enfermeiros deste estudo.

Poucos estudos foram realizados sobre essa temática, sendo assim importante destacar a contribuição deste estudo para compreender a prática do brincar e do BT para o enfermeiro de um hospital pediátrico na Região Sul do País.

A ampliação desse conteúdo em cursos de graduação em enfermagem, especialização e residência em enfermagem pediátrica e também a realização de novas pesquisas fazem-se necessárias na Região Sul do País.

A realização de cursos de capacitação sobre a tecnologia do Brinquedo Terapêutico para atender as necessidades e interesse dos enfermeiros participantes deste estudo é fundamental e necessária e pode ampliar a sistematização da assistência de enfermagem desse contexto hospitalar pediátrico.

\section{Referências}

1 Winnicott DW. O brincar e a realidade. Rio de Janeiro: Imago; 1975.

2 Ribeiro CA, Almeida FA, Borba RI. A criança e o brinquedo no hospital. In: Almeida FA, Sabates AL, coordenadores. Enfermagem pediátrica: a criança, o adolescente e sua família no hospital. São Paulo: Manole; 2008. p. 65-77.

3 Ribeiro CA, Borba RI, Rezende MA. O brinquedo na assistência à saúde da criança. In: Fujimori E, Ohara CV, organizadores. Enfermagem e a saúde da criança na atenção básica. São Paulo: Manole; 2009. p. 287-327. 
4 Pontes JED, Tabet E, Folkmann MAS, Cunha MLR, Almeida FA. Therapeutic play: preparing the child for the vaccine. Einstein. 2015;13(2):238-42. doi: 10.1590/S1679$45082015 \mathrm{AO} 2967$

5 Yogman M, Garner A, Hutchinson J, HirshPasek K, Golinkoff RM. The power of play: a pediatric role in enhancing development in young children. Pediatr. 2018;142(3). doi:10.1542/peds.2018-2058

6 Sposito AMP, Santos JLF, Pfeifer LI. Validation of the revised knox preschool play scale for the brazilian population. Occup Ther Int. 2019. doi:10.1155/2019/6397425

7 Rocha PK, Caleffi CCF, Anders JC, Souza AIJ, Burciaga VB, Serapião LS. Contribuição do brinquedo terapêutico estruturado em um modelo de cuidado de enfermagem para crianças hospitalizadas. Rev Gaúcha Enferm [Internet]. 2016 [citado 2018 set 16];37(2):18. Disponível em: https://seer.ufrgs.br/ RevistaGauchadeEnfermagem/article/ view/58131/37419

8 Li WHC, Chung OKJ. Enhancing the efficacy of psychoeducational interventions for paediatric patients in a randomised controlled trial: methodological considerations. J Clin Nurs [Internet]. 2009 [cited 2018 Oct 23];18(21):3013-21. Available from: https:// onlinelibrary.wiley.com/doi/epdf/10.1111/ j.1365-2702.2009.02913.x

9 Silva RD, Austregésilo SC, Ithamar L, Lima LS. Therapeutic play to prepare children for invasive procedures: a systematic review. J Pediatr [Internet]. 2017 [cited 2018 Oct 25]; 93(1): 6-16. Available from: https:// www.sciencedirect.com/sdfe/reader/pii/ S0021755716300961/pdf

10 Barreto LMSC, Maia EBS, Depianti JRB, Melo LL, Ohara CVS, Ribeiro CA. Dando sentido ao ensino do brinquedo terapêutico: a vivência de estudantes de enfermagem. Esc Anna Nery [Internet]. 2017 [citado 2018 jan 15];21(2):1-8. Disponível em: http://www. scielo.br/pdf/ean/v21n2/1414-8145-ean-2102-e20170038.pdf
11 Fernandes MNF, Chaves FL, Nunes JT, Costa ACPJ. O brincar na percepção de enfermeiros em um Hospital Pediátrico do Maranhão. J Health Sci [Internet]. 2017 [citado 2018 jan 15];19(2):120-5. Disponível em: http://www. pgsskroton.com.br/seer/index.php/JHealthSci/ article/view/3553/3563

12 Oliveira CS, Maia EBS, Borba RIH, Ribeiro CA. Brinquedo terapêutico na assistência à criança: percepção de enfermeiros das unidades pediátricas de um hospital universitário. Rev Soc Bras Enferm Ped [Internet]. 2015 [citado 2017 set 16];15(1):21-30. Disponível em: https://sobep.org.br/revista/images/stories/ pdf-revista/vol15-n1/vol_15_n_2-artigo-depesquisa-3.pdf

13 Conselho Nacional dos Direitos da Criança e do Adolescente (BR). Resolução 41, de 13 de outubro de 1995 [Internet]. 1995 [citado 2017 set 16]. Disponível em: http://www. mpdft.mp.br/portal/pdf/unidades/promotorias/ pdij/Legislacao\%20e\%20Jurisprudencia/ Res_41_95_Conanda.pdf

14 Conselho Federal de Enfermagem (BR). Resolução 546, de 9 de maio de 2017. Atualiza norma para utilização da técnica do brinquedo/brinquedo terapêutico pela equipe de enfermagem na assistência à criança hospitalizada [Internet]. 2017 [citado 2017 set 16]. Disponível em: http://www. cofen.gov.br/wp-content/uploads/2017/05/ Resolu\%C3\%A7\%C3\%A3o-546-17.pdf

15 Erickson FH. Reaction of children to hospital experience. Nurs Outlook [Internet]. 1958 [cited 2018 Oct 27];6(9):501-4. Available from: https://www.ncbi.nlm.nih.gov/ pubmed/13578214

16 Li WH, Chan SS, Wong EM, Kwok MC, Lee IT. Effect of therapeutic play on pre- and postoperative anxiety and emotional responses in Hong Kong Chinese children: a randomised controlled trial. Hong Kong Med J [Internet]. 2014 [cited 2018 Oct 27];20(7):36-9. Available from: http://www.hkmj.org/system/files/ hkm1406sp7p36.pdf 
17 Freitas BHBM, Voltani SSAA. Brinquedo terapêutico em serviço de urgência e emergência pediátrica: revisão integrativa de literatura. Cogitare Enferm [Internet]. 2016 [citado 2018 out 27];21(1):1-8. Disponível em: https://revistas.ufpr.br/cogitare/article/ view/40728/27245

18 Fontes CMB, Oliveira ASS, Toso LA. Brinquedo terapêutico em unidade de terapia intensiva pediátrica. Rev Enferm UFPE On Line [Internet]. 2017 [citado 2018 out 27]; 11(7): 2907-15. Disponível em: https://periodicos. ufpe.br/revistas/revistaenfermagem/article/ view/9518/19200

19 Tsai YL, Tsai SC, Yen SH, Huang KL, Mu PF, Liou HC, et al. Efficacy of therapeutic play for pediatric brain tumor patients during external beam radiotherapy. Childs Nerv Syst [Internet]. 2013 [cited 2018 Oct 27];29(7):1123-9. Available from: https://link.springer.com/artic le/10.1007\%2Fs00381-013-2099-3

20 Paladino CM, Carvalho R, Almeida FA. Brinquedo terapêutico no preparo para a cirurgia: comportamentos de pré-escolares no período transoperatório. Rev Esc Enferm USP [Internet]. 2014 [citado 2018 out 27];48(3):4239. Disponível em: http://www.periodicos.usp. br/reeusp/article/view/84106/86970

21 He HG, Zhu L, Chan SW, Liam JL, Li HC, Ko SS, et al. Therapeutic play intervention on children's perioperative anxiety, negative emotional manifestation and postoperative pain: a randomized controlled trial. J Adv Nurs [Internet]. 2015 [cited 2018 Oct 27]; 71(5): 1032-43. Available from: https://onlinelibrary. wiley.com/doi/pdf/10.1111/jan.12608

22 Oliveira CS, Maia EBS, Borba RIH, Ribeiro CA. Brinquedo terapêutico na assistência à criança: percepção de enfermeiros das unidades pediátricas de um hospital universitário. Rev Soc Bras Enferm Ped [Internet]. 2015 [citado 2020 jan 25];15(1):21-30. Disponível em: https://sobep.org.br/revista/images/stories/ pdf-revista/vol15-n1/vol_15_n_2-artigo-depesquisa-3.pdf
23 Costa DTL, Veríssimo MOR, Toriyama ATM, Sigaud CHS. O brincar na assistência de enfermagem à criança: revisão integrativa. Rev Soc Bras Enferm Ped [Internet]. 2016 [citado 2018 out 27];16(1):36-43. Disponível em: https://sobep.org.br/revista/images/stories/ pdf-revista/vol16-n1/vol_16_n_1-artigo-derevisao-1.pdf

24 Fernandes MNF; Chaves FL; Nunes JT; Costa ACPJ. O brincar na percepção de enfermeiros em um hospital pediátrico do Maranhão. J Health Sci [Internet]. 2017 [citado 2020 jan 25];19(2):120-5. Disponível em: https://revista.pgsskroton.com/index. php/JHealthSci/article/view/3553/3563. doi: 10.17921/2447-8938.2017v19n2p120-125.

25 Nascimento LCN, Souza TV, Oliveira ICS, Moraes JRMM, Aguiar RCB, Silva LF. Saturação teórica em pesquisa qualitativa: relato de experiência na entrevista com escolares. Rev Bras Enferm [Internet]. 2018 [citado 2019 jan 9];71(1):228-33. Disponível em: http://www.scielo.br/pdf/reben/v71n1/ pt_0034-7167-reben-71-01-0228.pdf. doi: 10.1590/0034-7167-2016-0616.

26 Minayo MCS. O desafio do conhecimento: pesquisa qualitativa em saúde. 10. ed. São Paulo: Hucitec; 2013.

27 Ministério da Saúde (BR). Resolução no 466, de 12 de dezembro de 2012 [Internet]. 2012 [citado 2017 set 16]. Disponível em: https://conselho. saude.gov.br/resolucoes/2012/Reso466.pdf

28 Santos DR, Bonfim CMS, Mazza VA, Wall ML, Mercês NNA. Processo de brincar da criança hospitalizada guiado pelo modelo lúdico. Cogitare Enferm [Internet]. 2014 [citado 2018 out 27];19(3):617-20. Disponível em: https://revistas.ufpr.br/cogitare/article/ view/36669/23261

29 Presidência da República (BR). Lei no 11.104, de 21 de março de 2005. Dispõe sobre a obrigatoriedade de instalação de brinquedotecas nas unidades de saúde que ofereçam atendimento pediátrico em regime de internação [Internet]. 2005 [citado 2017 set 16]. Disponível em: http:// www.planalto.gov.br/ccivil_03/_Ato20042006/2005/Lei/L11104.htm 
30 Marques DKA, Silva KLB, Cruz DSM, Souza IVB. Benefícios da aplicação do brinquedo terapêutico: visão dos enfermeiros de um hospital infantil. Arq Ciênc Saúde [Internet]. 2015 [citado 2018 set 15]; 22(3): 64-8. Disponível em: http://www.cienciasdasaude. famerp.br/index.php/racs/article/view/240/102

31 Lucietto GC, Lima LTS, Gleriano JS, Justi J, Silva RA, Borges AP. Brinquedoteca como ferramenta auxiliar no cuidado hospitalar: percepção de profissionais de enfermagem. Rev Saúde Desenvolv [Internet]. 2018 [citado 2018 set 16];12(10):88-103. Disponível em: https://www.uninter.com/revistasaude/ index.php/saudeDesenvolvimento/article/ view/870/517 